Thus a true $g$-inverse $X-=X_{0}-S$ is now obtained by subtracting each of the elements of $X_{0}$ by the corresponding elements of $S$ as obtained from $\alpha, \beta, \theta$ and $\mu$. The work involved will be less cumbersome if $A$ and $D$ are dirgonals.

Certain problems in the analysis of variance with unequal subclass numbers were posed by Prof. C. H. Hamilton, who will be publishing a paper on the subject very shortly.

North Carolina State College,

J. C. KooP

Department of Experimental Statistics, Raleigh, North Carolina.

${ }^{1}$ Rao, C. R., J. Roy. Statist. Soc., B, 24 (1), 152 (1962).

\section{Expressions for Combining Standard Errors of Two Groups and for Sequential Standard Error}

Most research workers have had occasion, during the course of several investigations, to combine two groups of quantitative results which show no statistically significant difference either in their means $\left(m_{1}\right.$ and $\left.m_{2}\right)$ or in their variances $\left(V_{1}\right.$ and $\left.V_{2}\right)$ and standard orrors $\left(e_{1}\right.$ and $\left.e_{2}\right)$. It is usually irksome to have to go back to the original data of both groups in order to calculate the new variance and standard error. Worse still, the original values may not be always available, and lengthy retrograde calculations of the sums of squares would then be required before the combined standard error could be obtained. Evidently, a simple expression relating the new standard error $\left(e_{3}\right)$ to the original standard errors and means would be most useful for both research workers and statisticians. We have therefore investigated this problem and have found the following simple relationship:

$e_{3}^{3}=\frac{1}{n(n-1)}\left[n_{1}\left(n_{1}-1\right) e_{1}^{2}+n_{2}\left(n_{2}-1\right) e_{2}^{2}+\frac{n_{1} n_{2}}{n}\left(m_{1}-m_{2}\right)^{2}\right]$

where $n_{1}, n_{2}$ refer to the number of observations in the first and second group respectively, and $n=n_{1}+n_{2}$.

Most research workers have also had occasion to collect observations which come in slowly as single items of measurement. A simple expression which gives a rapid method for calculating the new standard error after each additional measurement $\left(X_{n}\right)$ would therefore prove welcome. This situation represents in fact $a_{n}$ speciod case of equation (1), where $n_{2}=1$ and $m_{2}=X_{n_{1+1}}=X_{n}$. Equation (1) then yields the simple formula:

$$
e_{2}^{2}=\frac{n_{1}-1}{n} e_{1}^{2}+\frac{\left(m_{1}-X_{n}\right)^{2}}{n^{2}}
$$

where $n$ is now equal to $n_{1}+1$.

Proof. Considering the general case where $n_{1}$ and $n_{2}$ represent any number of observations in groups 1 and 2, we may write:

so that:

$$
e_{1}^{2}=\frac{\Sigma X_{1}^{2}-n_{1} m_{1}^{2}}{n_{1}\left(n_{1}-1\right)}, e_{2}^{2}=\frac{\Sigma X_{2}^{2}-n_{2} m_{2}^{2}}{n_{2}\left(n_{2}-1\right)}
$$

$$
e_{8}^{2}=\frac{\Sigma X_{1}^{2}+\Sigma X_{2}^{2}-\frac{\left(n_{1} m_{1}+n_{2} m_{2}\right)^{2}}{n_{1}+n_{2}}}{\left(n_{1}+n_{2}\right)\left(n_{1}+n_{2}-1\right)}
$$

where $X_{1}$ and $X_{2}$ represent tho sorios of individual messurements in groups 1 and 2 respectively. Expanding the term $\left(n_{1} m_{1}+n_{2} m_{2}\right)^{2}$ in equation (3) into $n_{1}^{2} m_{1}^{2}+n_{2}^{2} m_{2}^{2}+$ $2 n_{1} n_{2} m_{1} m_{2}$, substituting $-n_{1} m_{1}^{2}+\frac{n_{1} n_{2} m_{1}^{2}}{n_{1}+n_{2}}$ for $\frac{-n_{1}^{2} m_{1}^{2}}{n_{1}+n_{2}}$, and the corresponding expression for $-\frac{n_{2}^{2} m_{2}^{2}}{n_{1}+n_{2}}$, we obtain, after self-evident rearrangement of terms:

$$
\begin{aligned}
e_{3}^{2}=\frac{1}{n(n-1)}\left[\Sigma X_{1}^{2}-n_{1} m_{1}^{2}+\Sigma X_{2}^{2}-n_{2} m_{2}^{2}+\right. \\
\left.\frac{n_{1} n_{2}}{n}\left(m_{1}^{2}+m_{2}^{2}-2 m_{1} m_{2}\right)\right]
\end{aligned}
$$

which reduces to equation (1) directly.

$$
\text { R. W. R. BAKER }
$$

Department of Chemical Pathology,

$$
\text { J. A. Nissim }
$$

$$
\begin{gathered}
\text { Department of Pharmacology, } \\
\text { Guy's Hospital Medical Sehool, } \\
\text { London, S.E.1. }
\end{gathered}
$$

\section{MISCELLANEOUS}

\section{An Apparatus for Sterilizing Heat-labile Solutions}

Posirive pressure filtration for the sterilization of fluids avoids the risks of suck-back from the pump and prevents concentration of the fluid by evaporation. It is, however, more difficult to ensure sterile collection of the filtrate. The apparatus shown in Fig. 1 minimizes the risks of infection. The narrow funnel containing the glass sinter fits into an elongated bell-housing, its stem projecting into a Universal container, wedged into the housing with cotton-wool.

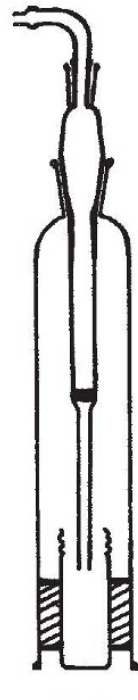

Fig. 1

The apnaratus is constructed of 'Pyrex' brand glass and 'Quickfit' connexions are used. The housing joint is sealed with silicone grease, the top joint being dry.

The filter used is a grade 5 'Pyrex' brand sintered glass filter of average pore diameter of $1 \cdot 1-1 \cdot 2 \mu$ and an air permeability greater than $0.1 \mathrm{ml} . \mathrm{min} / \mathrm{cm}^{2} / 1 \mathrm{~cm}$ water pressure. It is heat sealed to the 'Quickfit' connexion, care being taken not to damage the sinter during this process.

The whole apparatus is first sterilized by heat in an oven for $0.5 \mathrm{~h}$ at $180^{\circ} \mathrm{C}$. The solution to be sterilized is poured into the funnel, a positive pressure of four pounds per square inch from a nitrogen cylinder applied, and the sterile filtrate collects in the Universal container, which may be replaced when full.

\section{G. Godprey}

Medisal Research Council Unit for Research on the Experimental Pathology of the Skin, The Modical School,

University of Birmingham. 